\title{
Dawn phenomenon in Type 1 (insulin-dependent) diabetic adolescents: influence of nocturnal growth hormone secretion
}

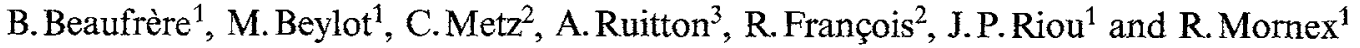 \\ ${ }^{1}$ INSERM U. 197, Faculté de Médecine Alexis Carrel, ${ }^{2}$ Department of Paediatrics, Hôpital Edouard Herriot, and \\ ${ }^{3}$ INSERM U. 34, Hôpital Debrousse, Lyon, France
}

\begin{abstract}
Summary. In order to reassess the role of growth hormone in the dawn phenomenon, we studied eight $C$-peptide negative diabetic adolescents, who are likely to exhibit important nocturnal growth hormone surges. The insulin infusion rate necessary to maintain euglycaemia was predetermined in each patient from 22.00 hours to 01.00 hours, and then kept constant until 08.00 hours resulting in stable free insulin levels. Blood glucose rose from $4.3 \pm 0.7 \mathrm{mmol} / 1$ at 01.00 hours to $7.1 \pm 1.1 \mathrm{mmol} / 1$ at 08.00 hours $(p<0.01)$ secondary to an increased hepatic glucose production. All the subjects presented an important growth hormone secretion, ranging from 20 to $66 \mathrm{ng} / \mathrm{ml}$ (peak values) and from 3619 to $8621 \mathrm{ng} \cdot \mathrm{min} \cdot \mathrm{ml}^{-1}$ (areas under the curve). The insulin infusion rate selected for each patient was positively correlated
\end{abstract}

with the nocturnal growth hormone secretion (area under the curve) $(r=0.87, p<0.01)$. On the other hand, there was no relationship between the nocturnal growth hormone secretion and the magnitude of the early morning blood glicose rise $(r=-0.48, p>0.2)$. We conclude that, in Type 1 (insulin-dependent) diabetic adolescents, the dawn phenomenon exists but is moderate despite important growth hormone surges; the nocturnal growth hormone secretion influences the nocturnal insulin requirements but not the dawn phenomenon itself, if insulinisation is adequate.

Key words: Dawn phenomenon, Type 1 (insulin-dependent) diabetes, adolescent, growth hormone.
The term "dawn phenomenon" indicates a condition in which insulin requirements increase between 04.00 hours and 08.00 hours (or hyperglycaemia develops if the increased insulin requirements are not met) in the absence of declining insulin delivery or preceding hypoglycaemia [1]. The dawn phenomenon has been extensively studied in adults with Type 1 (insulindependent) [2-12] or Type 2 (non-insulin-dependent) diabetes [11] and in normal subjects [13]. However, there are no data available on its possible occurrence in Type 1 diabetic children and adolescents, in whom elevated pre-breakfast blood glucose (BG) are a common clinical observation. If, as shown by some authors [3, 4], nocturnal growth hormone $(\mathrm{GH})$ secretion is the main determinant of the dawn phenomenon, this latter should be particularly apparent in diabetic adolescents since these subjects present an important GH secretion both because of puberty and diabetes [14-17].

We therefore studied 8 children and adolescents with Type 1 diabetes, at various pubertal stages, in order to answer the two following questions: (1) Does the dawn phenomenon exist in these adolescents? (2) If yes, is the magnitude of dawn phenomenon related to nocturnal GH secretion, which would further support a major role of $\mathrm{GH}$ in its pathogenesis?

\section{Subjects and methods}

\section{Patients}

After approval of this study by our local Ethical Committee, informed consent was obtained from eight children and adolescents with Type 1 diabetes and from their parents. The patients ( 6 girls, 2 boys) were 8.2 to 19.2 years old (mean $\pm S E M=14.1 \pm 1.2$ years), had been diabetic from 2 to 6 years $(4.3 \pm 0.4$ years) and had a fasting $C$ peptide below the limit of detectability of our assay $(0.05 \mathrm{nmol} / \mathrm{l})$. They were on a therapeutic regimen of 2 daily injections of a mixture of regular and intermediate acting insulins. Their glycosylated haemoglobin $\left(\mathrm{HbA}_{1}\right.$, column chromatography) was $8.8 \pm 0.8$ (normal range $=5-8.5 \%$ ). All of them had normal growth and their weight was within $2 \mathrm{SD}$ of the normal body weight for their height. They were of various Tanner pubertal stages (Table 1), and therefore, presumably presented a wide range of $\mathrm{GH}$ nocturnal secretion.

\section{Protocol}

Intermediate acting and regular insulins were withdrawn $24 \mathrm{~h}$ and $7 \mathrm{~h}$ before admission ( $30 \mathrm{~h}$ and $13 \mathrm{~h}$ prior to the first blood sampling). The subjects were admitted to the hospital at 16.00 hours on 
Table 1. Clinical characteristics, insulin infusion rates, growth hormone nocturnal secretion and pre-breakfast increase of blood glucose in eight Type 1 (insulin-dependent) diabetic adolescents receiving a constant overnight insulin infusion

\begin{tabular}{|c|c|c|c|c|c|c|c|c|c|c|c|c|c|}
\hline Subjects & $\begin{array}{l}\text { Age } \\
\text { (years) }\end{array}$ & $\begin{array}{l}\text { Tanner } \\
\text { pubertal } \\
\text { stage }\end{array}$ & Sex & $\begin{array}{l}\text { Glycosylated } \\
\text { haemoglobin } \\
(\%)\end{array}$ & $\begin{array}{l}\text { Diabetes } \\
\text { duration } \\
\text { (years) }\end{array}$ & $\begin{array}{l}\text { Daily insulin } \\
\text { requirements } \\
\text { (Units/kg } \\
\text { body weight) }\end{array}$ & $\begin{array}{l}\text { Insulin } \\
\text { infusion rate } \\
\left(\mathrm{mU} \cdot \mathrm{kg}^{-1}\right. \\
-\min ^{-1}\end{array}$ & $\begin{array}{l}\text { Peak } \\
\text { growth } \\
\text { hormone } \\
(\mathrm{ng} / \mathrm{ml})\end{array}$ & $\begin{array}{l}\text { Peak time } \\
\text { (clock } \\
\text { time) }\end{array}$ & $\begin{array}{l}\text { Number of } \\
\text { growth } \\
\text { hormone } \\
\text { peaks } \\
>7.5 \mathrm{ng} / \mathrm{ml}\end{array}$ & $\begin{array}{l}23.00 \text { hours- } \\
01.00 \text { hour } \\
\text { growth } \\
\text { hormone } \\
\text { secretion } \\
\text { ng } \cdot \text { min } \cdot \mathrm{mal}^{-1}\end{array}$ & $\begin{array}{l}23.00 \text { hours- } \\
08.00 \text { hours } \\
\text { overnight } \\
\text { growth hormone } \\
\text { secretion } \\
\left(\mathrm{ng} \cdot \mathrm{min} \cdot \mathrm{ml}^{-1}\right)^{\mathrm{a}}\end{array}$ & $\begin{array}{l}\text { Early moming } \\
\text { blood glucose } \\
\text { increase }(\%)^{b}\end{array}$ \\
\hline 1 & 8.2 & I & $F$ & 8.2 & 2.2 & 0.8 & 0.19 & 20 & 3.00 & 3 & 1626 & 4810 & +92.9 \\
\hline 2 & 12.8 & II & $M$ & 6.6 & 4.0 & 0.9 & 0.26 & 25 & 4.40 & 2 & 175 & 3740 & +10.8 \\
\hline 3 & 12.7 & III & M & 10.6 & 4.9 & 0.8 & 0.25 & 30 & 4.20 & 2 & 1632 & 4150 & +132.0 \\
\hline 4 & 13.9 & III & $\mathrm{F}$ & 10.0 & 3.1 & 0.7 & 0.40 & 66 & 0.20 & 2 & 5280 & 8621 & +30.9 \\
\hline 5 & 12.7 & IV & $F$ & 8.4 & 5.5 & 1.3 & 0.44 & 47 & 11.00 & 4 & 3342 & 7604 & -13.6 \\
\hline 6 & 15.8 & IV & $\mathrm{F}$ & 12.7 & 4.8 & 1.3 & 0.29 & 34 & 2.20 & 2 & 2358 & 6512 & +67.8 \\
\hline 7 & 17.6 & $\mathrm{~V}$ & $\mathbf{F}$ & 8.0 & 4.5 & 1.0 & 0.18 & 23 & 0.40 & 2 & 1158 & 3619 & +78.6 \\
\hline 8 & 19.2 & $\mathrm{~V}$ & $\mathrm{~F}$ & 5.9 & 6.0 & 1.2 & 0.26 & 25 & 4.20 & 3 & 1734 & 4446 & +50.0 \\
\hline mean & 14.1 & & & 8.8 & 4.3 & 1.0 & 0.28 & 34 & & & 2163 & 5438 & +56.2 \\
\hline SEM & 1.2 & & & 0.8 & 0.4 & 0.1 & 0.03 & 5 & & & 549 & 671 & +16.6 \\
\hline
\end{tabular}

a integrated nocturnal growth hormone secretion is calculated as the area under the curve (one sample every $20 \mathrm{~min}$ );

${ }^{b}$ percentage of increase of blood glucose is calculated as [06.40 hours-08.00 hours blood glucose (4 values)] - [01.00 hours-03.00 hours blood glucose (4 values)]/[01.00 hours-03.00 hours blood glucose $] \times 100$

the study day. A 14-gauge catheter was inserted in a superficial forearm vein for insulin infusion. Regular insulin (Actrapid HM, Novo, Denmark, Copenhagen) was diluted in normal saline to a final concentration of $1 \mathrm{U} / \mathrm{ml}$. The first few mls of solution were allowed to stand for $30 \mathrm{~min}$ in the plastic tubing and then discarded in order to saturate insulin absorption sites [18]. The same syringe and tubing were used throughout the entire study. Insulin was infused by means of a calibrated syringe pump (Robomedic 100, Gazuit Electronic, Domerat, France). A 20-gauge butterfly needle was inserted on the contralateral forearm for blood sampling and kept patent with normal saline $(10 \mathrm{ml} / \mathrm{h})$. Since the quality of sleep is a major determinant of nocturnal GH secretion [19], it was essential to avoid any noise or movement near the patient and therefore blood sampling was performed by the investigator standing in an adjacent room through a 3 meter long tube. For each sample, the plastic tubing was first purged from saline and blood, a blood sample was withdrawn and finally the initially withdrawn blood and saline were slowly reinjected in order to minimise blood substraction.

The patients were rendered euglycaemic between 16.30 hours and 19.00 hours by an insulin infusion adjusted on frequent (5-15 min) BG determinations performed in duplicate with a reflectance meter (Dextrostix and Glucometer, Ames Company, Paris, France), which was carefully calibrated and double checked with an enzymatic blood glucose (BG) determination prior to each study.

At 19.00 hours, a standard meal was given $(25 \%$ of the usual daily caloric intake, $50 \%$ carbohydrates, $35 \%$ fat, $15 \%$ protein) together with a bolus of insulin of approximately $1 \mathrm{U} / 10 \mathrm{~g}$ of carbohydrates. Patients were again rendered euglycaemic between 21.30 hours and 22.30 hours by adjusting the insulin infusion rate.

At 22.00 hours, a primed (approximately $4 \mathrm{mg} / \mathrm{kg}$ ) constant (approximately $0.027 \mathrm{mg} \cdot \mathrm{kg}^{-1} \cdot \mathrm{min}^{-1}$ ) infusion of $\mathrm{D}-\left[6,6^{2} \mathrm{H}_{2}\right]$ glucose (CEA, Gif-sur-Yvette, France) was begun and continued throughout the study $(n=7)$. Between 22.00 hours and 01.00 hours, the insulin infusion rate needed to keep each subject euglycaemic (4.5-5.5 mmol/1) was carefully determined and then kept constant from 01.00 hours (at the latest) to 08.00 hours. No hypoglycaemia occurred in any patient during the study.

Blood was withdrawn at $40 \mathrm{~min}$ intervals from 01.00 hours to 08.00 hours for determination of $\mathrm{BG}$, metabolites, $\left[6,6^{2} \mathrm{H}_{2}\right]$ glucose enrichment, free insulin and glucagon and at $20 \mathrm{~min}$ intervals from 23.00 hours to 08.00 hours for determination of plasma GH levels.

All the patients were sleeping by 23.00 hours and woke up between 07.15 and 08.00 hours.

\section{Analytical procedure}

Blood glucose, 3-hydroxybutyrate and plasma non-esterified fatty acids (NEFA) were assayed enzymatically as previously described [20]. Plasma D-[6, $\left.6^{2} \mathrm{H}_{2}\right]$ glucose enrichments were determined by gas chromatography-mass spectrometry using the bisbutane boronyl acetyl derivative of glucose, as previousiy described [21, 22]. Plasma levels of CPeptide [23], free insulin [23], glucagon [24] and GH [25] were determined by radioimmunoassay. At GH plasma levels of 2.6, 6.4 and $20 \mathrm{ng} / \mathrm{ml}$, the within and between assay coefficients of variation were, respectively $6.8 \%, 3.2 \%, 2 \%$ and $9.7 \%, 8.8 \%, 5.5 \%$.

\section{Statistical analysis}

Rates of glucose production and utilisation were calculated by the non-steady state equations of de Bodo [26] using a pool fraction of 0.5 . Integrated secretion of GH (area under the curve) was determined by the trapezoidal rule. Data are given as mean \pm SEM. Statistical analysis was done by two-way analysis of variance and paired Student's t-tests.

\section{Results}

The insulin infusion rate, determined in each patient between 22.00 hours and 01.00 hours, ranged from 0.18 to $0.44 \mathrm{mU} \cdot \mathrm{kg}^{-1} \cdot \mathrm{min}^{-1}$ (Table 1 ) due to individual variation of insulin sensitivity. This rate was not changed after 01.00 hours and resulted in stable plasma free insulin levels for the rest of the night, as seen in Figure 1 (mean 01.00-0.300 hours values: $23.1 \pm 2.4 \mu \mathrm{U} / \mathrm{ml}$; mean $05.40-07.40$ hours values: $21.3 \pm 1.9 \mu \mathrm{U} / \mathrm{ml})$. Accordingly, the insulin metabolic clearance rate did not change either $(14.8 \pm 4.0$ $\mathrm{ml} \cdot \mathrm{min}^{-1} \cdot \mathrm{kg}^{-1}$ vs $14.9 \pm 2.9 \mathrm{ml} \cdot \mathrm{min}^{-1} \cdot \mathrm{kg}^{-1}$ for the same periods). Plasma glucagon remained stable overnight $(01.00$ hours, $\quad 113 \pm 11 \mathrm{pg} / \mathrm{ml} ; \quad 07.40$ hours, $110 \pm 10 \mathrm{pg} / \mathrm{ml})$. BG did not change significantly from 


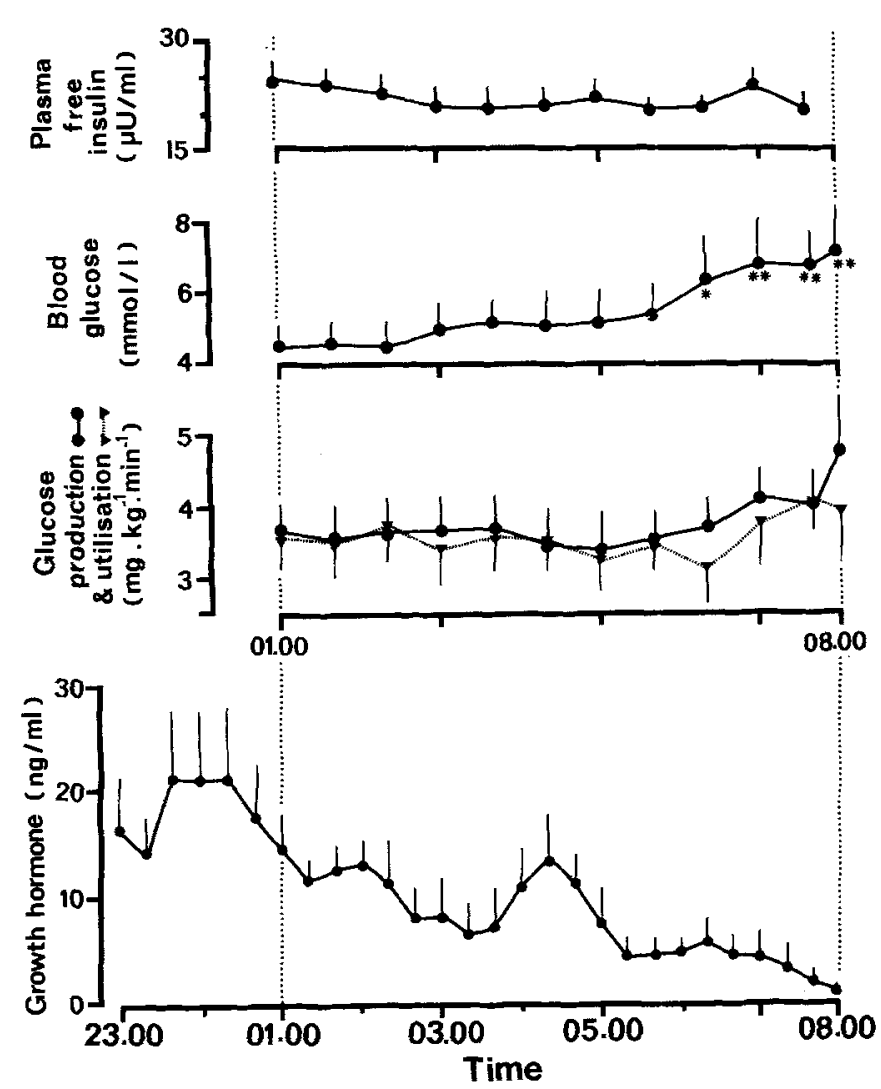

Fig. 1. Overnight metabolic profiles of plasma free insulin, blood glucose, rates of glucose production $(-)$ and utilisation $(\boldsymbol{\nabla})$ and plasma growth hormone levels in eight Type 1 (insulindependent) diabetic adolescents given a constant insulin infusion. Values are mean $\pm \mathrm{SEM} \cdot{ }^{*} p<0.05 ;{ }^{* *} p<0.01$ compared with $01.00-03.00$ hours values

01.00 hours $(4.32 \pm 0.70 \mathrm{mmol} / \mathrm{l})$ to 05.40 hours $(5,24 \pm 1.05 \mathrm{mmol} / \mathrm{l})$ and then rose to $7.14 \pm 1.15$ $\mathrm{mmol} / 1$ at 08.00 hours ( $p<0.01$ vs $01.00-03.00$ hours values). The mean early morning (06.40-08.00 hours) BG value increased by $50 \%$ or more above the mean $01.00-03.00$ hours value in 5 out of 8 patients (Table 1). There was an inverse relationship between this $\mathrm{BG}$ increase and the individual insulin infusion rate $(r=-0.689, p<0.05)$. Hepatic glucose production $(n=7)$ was stable from 01.00 hours $(3.66 \pm 0.38 \mathrm{mg}$ $\left.\mathrm{kg} \cdot{ }^{-1} \mathrm{~min}^{-1}\right)$ to 05.00 hours $\left(3.35 \mathrm{mg} \cdot \mathrm{kg}^{-1} \cdot \mathrm{min}^{-1}\right)$ and then increased moderately to $4.74 \mathrm{mg} \cdot \mathrm{kg}^{-1}$. $\mathrm{min}^{-1}$ at 08.00 hours (Fig. 1). This rise was not significant $(p>0.05)$ because of different time courses from one patient to another. However, the rise of BG and hepatic glucose production (expressed as percentage of increase between the $06.40-08.00$ hours values and the $01.00-03.00$ hours values) were positively correlated $(r=0.74, p<0.05)$. Glucose utilisation decreased slightly, but non-significantly from 01.00 hours to 06.40 hours and then followed the rise of glucose production. Plasma non-esterified fatty acids (NEFA) levels did not change (01.00 hours, $501 \pm 98 \mu \mathrm{mol} / 1$; 08.00 hours, $556 \pm 118 \mu \mathrm{mol} / \mathrm{l}$ ) while 3-hydroxybutyrate tended to increase although nonsignificantly
( $p>0.05) \quad(01.00$ hours, $92 \pm 12 \mu \mathrm{mol} / 1 ; 08.00$ hours, $217 \pm 55 \mu \mathrm{mol} / 1)$.

The mean values of plasma GH from 23.00 hours to 08.00 hours are depicted on the bottom panel of Figure 1. The chronological patterns of nocturnal GH secretion were very different from one subject to another (Table 1). All the patients presented at least one peak above $20 \mathrm{ng} / \mathrm{ml}$ and 2 peaks above $7.5 \mathrm{ng} / \mathrm{ml}$. Both peak GH values and areas under the curve appeared to be highest in subjects of Tanner pubertal stages III and IV.

There was a positive correlation between the insulin infusion rate delivered from 01.00 to 08.00 hours and the amount of GH (area under the curve) secreted either during the period of determination of this rate, i.e. from 23.00 to 01.00 hours $(r=0.775, p<0.05$ ) or during the whole night, i.e. from 23.00 to 08.00 hours $(r=0.87, p<0.01)$. On the contrary, no correlation was found between the nocturnal GH secretion (area under the curve) and the early morning rise of $B G$, whether this latter was expressed as the 08.00 hours $B G$ value $(r=-0.040, p>0.9)$ or as the absolute $(\mathrm{mmol} / \mathrm{l})$ or relative $(\%)$ increase of $\mathrm{BG}$ between dawn (06.40-08.00 hours) and the $01.00-03.00$ hours period (respectively, $r=-0.152, p>0.6$ and $r=-0.478$, $p>0.2)$.

\section{Discussion}

Our data demonstrate that Type 1 diabetic adolescents receiving a constant, but individually predetermined overnight insulin infusion, present a moderate early morning $\mathrm{BG}$ rise. The insulin infusion rates were determined on the basis of bedside venous BG determination, using a reflectance meter, which is less accurate than a glucose analyser. However, extreme care was taken for these measurements (see Methods section) which were very close to the actual BG measured later on by an enzymatic method. The fact that the insulin infusion rates selected on this basis were able to maintain euglycaemia until 05.30 hours indicate that these rates were adequate for each patient.

Elevated pre-breakfast BG is a common feature in Type 1 diabetic patients and recognises three causes that can be additive: post-hypoglycaemic hyperglycaemia, underinsulinisation and dawn phenomenon. (1) Hypoglycaemia did not occur in any of our patients which therefore excludes a rebound hyperglycaemia (Somogyi phenomenon). In keeping with this, the observed $\mathrm{GH}$ secretion was not the result of counterregulation and did correspond to a physiological GH profile. (2) Underinsulinisation is certainly relevant in clinical practice due to the waning of subcutaneously injected insulin. This was not the case in our subjects since BG, NEFA, ketone bodies and hepatic glucose production remained constant until approximately 06.00 hours and since plasma free insulin 
levels were stable overnight. (3) A dawn phenomenon does occur in Type 1 diabetic adolescents according to our data, and is secondary to an increased hepatic glucose production, as previously shown $[3,4]$, rather than to a decreased glucose utilisation. The rather elevated basal glucose production $\left(3.66 \mathrm{mg} \cdot \mathrm{kg}^{-1} \mathrm{~min}^{-1}\right)$ is related to the young age of our patients and our values are comparable to those found by Bier in normal adolescents (approximately $3.8 \mathrm{mg} \cdot \mathrm{kg}-1 \cdot \mathrm{min}^{-1}$ in $40 \mathrm{~kg}$ adolescents) [21]. The overall amplitude of the dawn phenomenon was lower (mean 08.00 hours BG: $7.1 \mathrm{mmol} / \mathrm{l}$ ) than in previous studies [3-5] in Type 1 diabetic adults (mean 08.00 hours BG, $9.3-12.9 \mathrm{mmol} /$ 1) using comparable protocols, i.e. a constant overnight insulin infusion.

The cause of the dawn phenomenon remains controversial. An increased metabolic clearance rate of insulin has been reported by many authors using a Biostator $[3,4,8,10,27]$. However, it was later shown $[5,28]$ that the rate of insulin delivered by the Biostator, decreased slowly with time, resulting in a decreasing insulin concentration, and therefore in an artefactual increase of insulin metabolic clearance rate. As a matter of fact, when insulin was delivered with a syringe pump, the insulin clearance either increased very little $[9,29]$ or only in a few patients [27], or did not change at all overnight $[5,12]$ which is further confirmed by our data.

Among the counterregulatory hormones, cortisol, glucagon and catecholamines have been successively ruled out $[3,7,8]$ as causes for the dawn phenomenon. On the contrary, $\mathrm{GH}$, which is able to induce insulin resistance [30,31] and is mostly secreted during sleep could influence nocturnal glucose homeostasis. Two different questions should be considered. First, does GH play a role on the overnight insulin requirements; and second, does it play a role on the pre-breakfast $\mathrm{BG}$ rise, i.e. the dawn phenomenon?

The answer to the first question is that GH increases the overnight insulin requirements in Type 1 diabetic patients. The insulin needs of our patients were positively correlated with the overnight $\mathrm{GH}$ secretion. This is in keeping with the data of Amiel et al. [17] who demonstrated a negative relationship between insulin sensitivity and mean $24 \mathrm{~h} \mathrm{GH}$ secretion in diabetic adolescents. Similarly, Skor et al. have shown that nocturnal insulin requirements decreased by approximately 30\% [10] when GH secretion was suppressed by somatostatin, this being true both from 01.00 to 03.00 hours and from 06.00 hours to 8.00 hours. Finally, the high GH levels observed in our patients, comparable to those previously reported in Type 1 diabetic adolescents $[14,17]$ probably account for their elevated insulin requirements.

Second, a role of GH on the dawn phenomenon strictly speaking is far from clear. We were unable to find any significant correlation between GH secretion and the magnitude of the dawn phenomenon. In the study by Skor et al. [10], the pre-breakfast increase in insulin requirement was not abolished by somatostatin. Mauras et al. [32] failed to detect a dawn phenomenon in normal subjects with markedly different patterns of GH secretion. These results are at variance with those of Campbell et al. [3, 4] who demonstrated a clear relationship between $\mathrm{GH}$ and the dawn phenomenon. A possible explanation for this discrepancy is that, in this latter study, all the patients received the same constant insulin infusion rate $\left(0.15 \mathrm{mU} \cdot \mathrm{kg}^{-1} \cdot \mathrm{min}^{-1}\right)$. Given the individual variability of insulin requirements, it is possible that some subjects had been underinsulinised and that, in these latter, the hyperglycaemic effect of $\mathrm{GH}$ has been progressively unmasked during the night, resulting in a rise of $\mathrm{BG}$ correlated with $\mathrm{GH}$ secretion. Finally, a relative overnight underinsulinisation could also account for the difference of magnitude of the dawn phenomenon between data of Campbell et al. and ours. It is of interest to note that the dawn phenomenon begins early ( 03.30 hours) when a standard insulin infusion is given $[3,4,27]$ while, on the contrary, it begins only at 05.30 hours when the patients receive a variable insulin infusion $[6,11,12]$ or an individually predetermined insulin infusion.

Other lines of evidence for a role of $\mathrm{GH}$ in the pathogenesis of the dawn phenomenon are also controversial. Its suppression by somatostatin was reported by Campbell [3] but not by Skor [10]. Finally, restoration of a dawn phenomenon by $\mathrm{GH}$ replacement (3) is difficult to interpret since normal GH plasma levels were obtained $30 \mathrm{~min}$ after intravenous injections of GH. Given the very short half life of intravenous $G H$, the actual peaks of GH were likely to be much higher than those observed and could have resulted in pharmacological, rather than physiological, levels.

In summary, the present study indicates that (1) a dawn phenomenon of moderate amplitude exists in Type 1 diabetic adolescents, (2) overnight insulin requirements are influenced by GH nocturnal secretion, (3) if overnight insulinisation is adequate, GH does not appear to play a major role in the dawn phenomenon strictly speaking. If underinsulinisation occurs in the early morning, which is the case when insulin is injected subcutaneously prior to dinner, it could potentialize the dawn phenomenon. Our data do not support the proposed suppression of GH nocturnal surges by somatostatin analogs, a treatment that, in any case, would be unconceivable in growing children.

Acknowledgments. We wish to thank Dr Barbieux for preparation of the tracers, Mrs M.Odeon for technical assistance and Mrs S. Terfous for secretarial help.

\section{References}

1. Perriello G, De Feo P, Bolli GB (1988) The dawn phenomenon: nocturnal blood glucose homeostasis in insulin dependent diabetes mellitus. Diabetic Med 5: 13-21 
2. Geffner ME, Frank HU, Kaplan SA, Lippe BM, Levin SR (1983) Early morning hyperglycemia in diabetic individuals treated with continuous subcutaneous insulin infusion. Diabetes Care 6: 135-139

3. Campbell PJ, Bolli GB, Cryer PE, Gerich JE (1985) Pathogenesis of the dawn phenomenon in patients with insulin-dependent diabetes mellitus. N Engl J Med 312: 1473-1479

4. Campbell PJ, Bolli GB, Cryer PE, Gerich JE (1985) Sequence of events during development of the dawn phenomenon in insulindependent diabetes mellitus. Metabolism 34: 1100-1104

5. Campbell P, Cryer PE, Gerich JE (1986) Occurrence of the dawn phenomenon without a change in insulin clearance in patients with insulin-dependent diabetes mellitus. Diabetes 35: 749-752

6. Clarke WL, Haymond MW, Santiago JV (1980) Overnight basal insulin requirements in fasting insulin dependent diabetics. Diabetes $29: 78-80$

7. Bright GM, Melton TW, Rogol AD, Clarke WL (1980) Failure of cortisol blockade to inhibit early morning increases in basal insulin requirements in fasting insulin dependent diabetics. Diabetes 29: 662-664

8. Skor DA, White HN, Thomas L, Shah SD, Cryer PE, Santiago JV (1983) Examination of the role of the pituitary-adrenocortical axis, counterregulatory hormones and insulin clearance in variable nocturnal insulin requirements in insulin-dependent diabetics. Diabetes 32: 403-407

9. Skor DA, White NH, Thomas L, Santiago JV (1984) Relative roles of insulin clearance and insulin sensitivity in the prebreakfast increase in insulin requirements in insulin-dependent diabetic patients. Diabetes 33:60 63

10. Skor DA, White HN, Thomas L, Santiago JV (1985) Influence of growth hormone on overnight insulin requirements in insulin-dependent diabetics. Diabetes 34: 135-139

11. Bolli GB, Gerich JE (1984) The "dawn phenomenon" - a common occurrence in both non insulin-dependent and insulindependent diabetes mellitus. N Engl I Med 310: 746-750

12. De Feo P, Perriello G, Ventura MM, Calcinaro F, Basta G, Lolli C, Cruciani C, Dell'Olio A, Santeusanio F, Brunetti P, Bolli GB (1986) Studies on overnight insulin requirements and metabolic clearance rate of insulin in normal and diabetic man: relevance to the pathogenesis of the dawn phenomenon. Diabetologia 29: $475-480$

13. Bolli GB, De Feo P, De Cosmo S, Perriello G, Ventura MM, Calcinaro F, Lolli C, Campbell P, Brunetti P, Gerich JE (1984) Demonstration of a dawn phenomenon in normal human volunteers. Diabetes 33: 1150-1153

14. Hayford JT, Danney MM, Hendrix JM, Thompson RG (1980) Integrated concentration of growth hormone in juvenile onset diabetes. Diabetes 29: 391-398

15. Horner JM, Kemp SF, Hintz RL (1981) Growth hormone and somatomedin in insulin dependent diabetes mellitus. J Clin Endocrinol Metab 53: 1148-1153

16. Press M, Tamborlane WV, Sherwin RS (1984) Importance of raised growth hormone levels in mediating the metabolic derangements of diabetes. N Engl J Med 310: 810-815

17. Amiel SA, Sherwin RS, Simonson DC, Lauritano AA, Tamborlane WV (1986) Impaired insulin action in puberty: a contributing factor to poor glycemic control in adolescents with diabetes. N Engl J Med 315: 215-219

18. Canivet B, Berre A, Macchi P, Grimaud D, Maestracci P, Freychet $P$ (1983) Absorption of insulin directly added to infusion bottles. Path Biol 31: 37-40
19. Parker DC, Sassin JF, Mace JW, Gotlin RW, Rossman LG (1969) Human growth hormone release during sleep: electroencephalographic correlation. J Clin Invest 29: 871-874

20. Beaufrere B, Beylot M, Riou JP, Serusclat P, Cohen R, Souquet JC, Mornex R (1983) Role of catecholamines in the ketonemic response to somatostatin in normal man. J Clin Endocrinol Metab 57: 847-850

21. Bier DM, Leake RD, Haymond MW, Amold KJ, Gruenke LD, Sperling MA, Kipnis DM (1977) Measurement of "true" production rates in infancy and childhood with 6,6-dideuteroglucose. Diabetes 26: 1016-1023

22. Beylot M, Khalfallah Y, Riou JP, Cohen R, Normand S, Mornex R (1986) Effects of ketone bodies on basal and insulinstimulated glucose utilization in man. J Clin Endocrinol Metab 63: $9-15$

23. Gerbitz KD, Kemmler W, Edelmann A, Summer J, Mehnert H, Wieland OH (1979) Free insulin, bound insulin, C peptide and the metabolic control in juvenile onset diabetes: comparison of $\mathrm{C}$ peptide secretors and non secretors during $24 \mathrm{~h}$ conventional insulin therapy. Eur J Clin Invest 9: 475-483

24. Ruitton A, Frederich F (1975) Specific radioimmunoassay of pancreatic glucagon: results in newborn and child. Diabete Metab 1: 143-150

25. Shalch DS, Parker ML (1964) A sensitive double antibody immunoassay for human growth hormone in plasma. Nature 203: $1141-1142$

26. De Bodo RC, Steele R, Altszuler N, Dunn A, Bishop JS (1963) On the hormonal regulation of carbohydrate metabolism: studies with C14 glucose. Recent Prog Horm Res 19: 445-488

27. Kerner W, Navascues I, Torres AA, Pfeiffer EF (1984) Studies on the pathogenesis of the dawn phenomenon in insulin-dependent diabetic patients. Metabolism 33: 458-464

28. Brennan JR, Gebhart SSP, Blackard WC (1985) Pump induced insulin aggregation: a problem with the Biostator. Diabetes 34 : 353-359

29. Dux S, White NH, Skor DA, Santiago JV (1985) Insulin clearance contributes to the variability of nocturnal insulin requirements in insulin-dependent diabetes mellitus. Diabetes 34: 1260-1265

30. Gerich JE, Lorenzi M, Bier DM, Tsalikian E, Schneider V, Karam JH, Forsham PH (1976) Effects of physiologic levels of glucagon and growth hormone on human carbohydrate and lipid metabolism. J Clin Invest 57: 875-884

31. Bratusch-Marrain PR, Smith D, De Fronzo RA (1982) The effect of growth hormone on glucose metabolism and insulin secretion in man J Clin Endocrinol Metab 55: 973-982

32. Mauras N, Rogol AD, Clarke WL (1986) Failure to detect the "dawn phenomenon" in non diabetic subjects with markedly different patterns of nocturnal growth hormone secretion. J Clin Endocrinol Metab 62: 975-979

Received: 29 February 1988

and in revised form: 31 May 1988

B. Beaufrère

INSERM U. 197

Faculté de Médecine Alexis Carrel

Rue G.Paradin

F-69372 Lyon Cédex 08

France 